\title{
The Pragmatic Analysis of Gurage Riddle
}

Shashetu Bayu Tizazu

(Ass.Prof.)

Department of English Language and Literature

College of Social Science and Humanities

Wolkite University

Wolkite, Ethiopia

shashetu.b@gmail.com

Kamil Nuredin Awol

MA in TEFL

Department of English Language and Literature

College of Social Science and Humanities

Wolkite University

Wolkite, Ethiopia

kamnure2007@gmail.com

Yibeltal Tadele

Department of English Language and Literature

College of Social Science and Humanities

Wolkite University 


\title{
Wolkite, Ethiopia
}

yibeltaltadele@gmail.com

\begin{abstract}
This paper is based on a pragmatic analysis of Gurage riddles that lay an important role in enlightening both children and adults as well. In line with this, it aimed to investigate how Gurage people discuss pragmatic discourses and introduce them into society over riddles. The data were collected through interviews from the local people and documents. The document 'Yegurage Wemaka' from which fourteen riddles were collected for analysis was the primary data gathering tool for the study. A purposive sampling technique was employed to choose the informants and the document which clearly contains Gurage riddles. The collected riddles were clustered according to their theme and grammatically founded meaning, and they are transcribed into alphabetic script since they were in Ethiopic scripts. Then, the pragmatic roles of the collected data were analyzed qualitatively from the perspectives of Relevance theory hence, the study focused on the interpretive aspects of riddles. The finding showed that pragmatically Gurage riddles play a great role to promote the culture of 'Enset' as the main source of food and its production, to introduce the materials that are used in their day to day life and way of house building (folk materials), to promote Gurage people's transportation system and infrastructures, to show as the coffee ceremony is the main social coexistence, to promote the culture of Gurage people agriculture, death, and destruction. Finally, it also found out that context and cultural knowledge play a major in interpreting and understanding Gurage riddles.
\end{abstract}

Keywords: Pragmatics, Gurage, Riddle, Relevance theory 


\section{Introduction}

\subsection{BackgroundtotheStudy}

As Finnegan (1970) states riddle as a form of folklore has long been a subject of considerable interest among folklorists, linguists, and specialists in area studies. She further shows that riddles, unlike proverbs, are regarded as a preserve for children and a kind of marginal activity presented at special times rather than a universal aspect of human activity and communication. Gurage refers to the people of south Ethio-Semitic language speaking groups living in the recent Gurage Zone of the Southern Nations, Nationalities and People Regional (SNNPR). Gurage people have different groups such as Sebat Bit, Sodo, Meskan, and Wolenie. The Gurage people share a similar culture and language. Their language; however, relatively varies in phonology, lexicon, and a few morphological features. Most of the varieties are closely related, hence, can be understood by different ethnic groups within Gurage (Gebreyesus, 1991). The formal features of riddle language such as the linguistic aspects of riddles have been largely ignored by folklorists. The present article focuses on the pragmatic discourses of Gurage riddles. Armstrong (2005) supports this view by saying that native speakers of a language can easily know the different uses of riddles based on culture and context. This view makes Gurage riddles no exception as it will help in interpreting and understanding Gurage riddles by the audience. Pragmatics is used in many settings like politics, anthropology, sociology, language, etc. The attempt is made in this study to show pragmatic discourse analysis into the society to achieve integration across people in all social and other aspects of the people through over riddle. Gurage language is extensively used at home, social places, and even at rural schools especially in lower primary schools and secondary apart from being a medium of instruction.

\subsection{Statement of the Problem}


This study attempts to analyze the pragmatic features of Gurage riddles. Previous studies show that scholars have been giving little consideration to Gurage oral literature in general and Gurage riddles in particular. The study defines sorts and relates Gurage riddles with respect to pragmatic perspectives and tried to show all social aspects of Gurage communities' life phenomena. It will further establish the role of setting and social acquaintance in interpreting Gurage riddles. According to Odaga (1984), a riddle is a short, witty statement or question, but which lacks the seriousness as of a proverb. Therefore, a riddle is a phrase that creates confusion or doubt and needs to be worked out. The issue of communication over received wisdom is less considered in the context of the Gurage Community. Therefore, it is less known how definite language speakers communicate their wishes, aspirations, and lived experiences, and how they shape with it the everyday life of their community of speakers. This study thus is aimed to partly fill in the existing gap. As the riddles are so various and discover all issues of life, the article is enclosed only to the pragmatic speeches of Gurage riddles.

\subsection{Objective of the Study}

\subsubsection{General Objective}

The general objective of the study is to collect, analyze and interpret the pragmatic feature of Gurage riddles.

\subsubsection{Specific Objectives}

The general objective is followed by the following three specific objectives: It is to:

- $\quad$ Find out the pragmatic features of riddles in representing the socio - cultural values of the Gurage people

- Examine the role of the cultural context in inferring and understanding Gurage riddles

- $\quad$ Categorize Gurage riddles in their order of importance as per their pragmatic aspects 


\section{Methods}

This section deals with the methods that are used to collect and analyze the pragmatic features of Gurage riddles. This study is a qualitative type of study. To collect the data interview and secondary sources or documents were employed. As a result, the book "yeguragewokama" was the main source of the data. It is prepared by Gurage Zone culture and tourism office. The Gurage riddles first identified and categorized in their thematic consideration to analyze according to their pragmatic features. Then, the identified data were transcribed into Alphabetic script. Then, the selected riddles were analyzed qualitatively according to the beliefs of Relevance Theory as a theoretical framework. Such perceptions of individuals and society are influenced by social norms, status, gender, political and social powers, and societal values (Plack, 2005). Thus, such an interpretive aspect of discourse is used as a methodology. A few examples were also adapted from Tenkir (1999) and Gurage Zone Culture Tourism (2012). The data were analyzed and presented based on the meanings in the riddles encoded. The themes were further categorized to show relationships that revolve around the meaning and idea of the riddle.

\section{Result}

In this paper speech of the riddles which are used as an organization and analysis of social values were stated and analyzed to infer their meaning. This assumption is based on Fairclough ${ }^{e e}$ (2003, p.4) Critical Discourse Analysis (CDA) which dictates speech analysis used in certain communities. This part of the study also deals with the Pragmatic analysis of Gurage riddles. Sperber and Wilson (2004:270) regard relevance theory as a revised theory contrary to the standard pragmatic model. Therefore, all the discussions are mentioned with various sections and subsections to depict the results related to the riddles. 
3.1 Riddles Related to the culture of 'Enset' and its product and other cultural food

This sub-section deals with riddles that give credit to the staple food of the people in the south of Ethiopia in general and the Gurage people in particular and show how the food has made a close link with these people. Most of the riddles are made just like question and answer, so the riddling process is made in line with its unique nature in relation with meaning of words and sentences in context (pragmatics). Since the Guarge riddles are recited in poetic forms, it requires phonetic transcription by considering the international arguments which are made by the scholars; the discussion has been made as like the English phonetic transcription as it is made by the speakers. Riddle in Guragina takes place just like question and answer which can be designated by the following ways: the person who is going to ask the question (questioner) will say "Niehe Enekuwit" and the one who is expected to give the response (answerer) will say "Nekuwi" and the process and the procedure will continue in this manner. Therefore, the riddling process will follow this pattern and fashion in order to make the riddle performance according to the structure and rule of Gurage riddling. In other words, the performance of Gurage riddle has a structure and has two main parts: opener and respondent.

\subsubsection{Ideas that promote 'Enset' as a source of food}

In Gurage people in particular and in many communities in the South in general use 'Eneset' and its product as a source of food. In many religious and national holidays, Eneset can be used across all societies. Even farmers who have small land to plow in the south of Ethiopia in general and in Gurage in particular, they arrange some part of their land for 'Eneset' because they took it as part of their life and the main source of food. From many 
other various kinds of riddles, five riddles that are associated to 'Enset' as a source of food are mentioned hereafter:

1. 'AshekareAshekare Teheterem; Seb Yareberem Tefetrerem'[A $\square$ eke:] [ta $\square$ eka:] [tehete:m] [seb] [ ja:berem] [tefete:m]

Response: 'Enset'

The English translation of this riddle connotes that 'Enset' shaded its self and appeared to save us. From this riddle, one can understand that Enset planted and appeared to be as a source of food to the people. The inference of this riddle is that a person who exerts effort by hiding himself can bring great success in their life in particular and on others in general. In this riddle, the Gurage people believe in future career fate by taking the present situation as a springboard to make changes in their life.

2. 'Yabana shehe afere yaze; Yadotena shehe sekure yaze.' [jabana] [ $\square$ ehe] [afe:] [jaz]

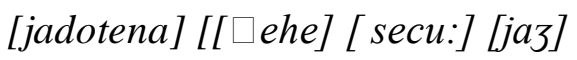

When we translate this riddle into English, it means that my father's spirit is viewing up, but my mother is pointing at down. Now, we know that the binding force between our mother and father is very strong and in everyone's life, they put their own critical fingerprint for effective life growth. Likewise, in this riddle, the idea is mentioned metaphorically with 'Enset' to show how Enset has grown and used. It shows that Enset when it is ready for food, it is served with Cabbage and it is highly associated with the way father and mother interrelated. Thus, by very nature, the Enset plant has the root and the left part. The edible part of Enset is found in the root part and the leave has a protective role. From this statement, we can notice that how these people have the tendency to make 'Enset' with the role of father and mother which can tell us how they have the intention to make interconnection with Enset 
culture within the family tree It shows that these people have a very close connection with 'Enset'.

\section{3. 'Tikebeweri Yemateta; Tiweta Tedenegiyata' [tikebuweri] [jemateta] [tiweta]}

\section{[ tedenegijata]}

This riddle literally translated as it was planted alone but it grew up with its child. This is to mean that at the time of plantation, it is plated with a single Enset plant, but it grows with other part being more than seven which can be used as a source of food. This idea by itself indicates how something at the very beginning is being treated as it is alone, but through time and with the exertion of certain effort, it will be duplicated as multiple sources. The Gurage people ironically express their feeling through effort, and their accomplishment becomes productive. From this, one can understand that a person who works for success can be successful at the end though there are ups and downs at the beginning.

(4) 'MeshetYareshechen Guweye; Mese Yabaneren' [me $\square$ et] [jare $\square$ et $\square$ en]

\section{[ guweje] [ mese] [jabuwaneren]}

This riddle translates as: A house-made by the wife and destroyed by her husband. The Gurage people use this riddle to connote and denote how the wife at home is very serious to prepare delicious and attractive food for her husband to show her due care and respect. Moreover, the traditional food which is named 'Zemuamuejat' is made for the people who are guests and loved by them. In relation to this, this traditional food is prepared with great care and served with respect by women only. In this context, the food is prepared for the husband and delivered with the product of 'Enset' named 'Kocho'. From this, we can understand that the Gurage people from ancient time to the present day use this traditional food to serve their close and respected associates.

\section{(5) 'BesechaYamete; Bekura Yechene’ [beset $\square$ a] [jamet] [ becura] [ jet $\square$ en]}


The literal definition of this riddle is defined as follows: It strives to give birth at the upper place and give birth at the lower position. Here the riddle has the answer 'ATEMETE' which is one of the other sub-products of Enset'. In this riddle, the Enset plant is grown and its result or product is found around the root. Among the various product of Eneset 'Atemet' is prepared as a byproduct 'Ensete' which is called 'Weheta' which is in Amharic called 'Amicho'. From this riddle, we can understand that traditional food is prepared at the time of special occasion.

\subsubsection{Issues related to food and households Utensils}

Traditional and national foods which are prepared for various ceremonies appreciated and expressed in different ways by Gurage society as can be proven in numerous riddles discussed below.

\section{1) 'AchemYederese' [at $\square$ em] [jederes]}

The answer to this riddle is traditional drinking called 'Sehere' which is equivalent to beer. The way of preparation between 'Sehere' and beer is almost the same because both 'Sehere' and beer use barley as an ingredient. In the process of 'Sehere' preparation and the process of fermentation, it is very common to close the pot in which we prepare the traditional drinking until it is ready to drink. In this riddle, society is explaining how it is prepared and makes use of it. This riddle expresses the condition in which people that use their freedoms are given to them without violating others' liberty and on the way they can benefit others. This tells us insignificant things should not get a place.

\section{2) 'EreseyeMese; Toreta Fuze[ eresej] [ mes] [ to:ta] [fuz]}

This riddle is said to focus on the spoon. The definition of the riddle is to mean that the spoon capacity is quite different from its weigh. As it is known the spoon is used by the 
Gurage society to have food like forage and other traditional food. What is more important is we can imagine and measure everything with their size, but it is essential to see and focus on the use they provide to the people across the world.

\section{3) 'EreseyeGered Hemie zemie Tebere’ [ eresej] [gered] hemea] [zemea]}

The answer to this riddle is a sweeper. This riddle is literally defined as follows: A little child moves stagger. The process of cleaning the house is associated with a little child. This is to means that the role of the sweeper has associated with the way a little child act. From this riddle, we can realize that the allegory has been made between the child she/he acts, and the way we clean house.

\subsubsection{Transportation and infrastructure}

The riddle in Gurage society encourages someone to move from one place to the other for multiple uses with the help of appropriate infrastructures. In doing so, movement is taken as a means of wealth as can be discussed from the following riddles:

\section{1) 'Yadotena Azegat Benetagoden Benetagoden Anareqe Bareme' [ jadotena]}

\section{[ azegat] [ bentagoden] [ benetagoden] [ anark] [ baream]}

The answer to this riddle is a road. This riddle literally translates as: My mother's belt folded many times, but infinite. Since the Gurage societies are mobile, they associate their life in relation to the road. Besides, in this riddle, we realize that the road is interwoven with the mother the kindest person in the world. This indicates that the Gurage community affiliated to the road as a means of transportation.

2) “Jewe Enene Ferese Jefewere Yekera” [dzew] [eanen] [ fe:se] [dzefewer] [ jecera]

This riddle has the following English equivalent: The horse with no tail passes across the gate. The answer to this riddle is the car. Now, car as a means of transportation is 
associated with the horse. In Gurage culture, the horse is used as a means of transportation to travel from one place to another. In the same way, car as a means of transportation metaphorically presented with the horse because the society dominantly uses the horse for transportation purpose. Therefore, the essence of this riddle is to make a link between horse and car for movement.

\section{3)'Biema Weriem Goga Weterem' [beama] [ weream] [ goga] [ wete:m]}

The above riddle translated to English as: around the street the cow skin stretched. This riddle is said to state the bridge. Here, the bridge as one of the infrastructures is mentioned in this riddle as a road which is associated with cow's skin. In this case, the stretched skin linked with the bridge.

\subsubsection{Coffee ceremony to promote social coexistence}

This section converses with the riddles that focus on the culture of the coffee ceremony. This kind of riddles concentrates on the way coffee is prepared and the ceremony in the process of coffee preparation. In doing so, people gathered together and discussed various social issues and then they improve their critical thinking which required effort in processing our utterance. The following riddles are associated with the culture of coffee.

\section{1) 'Adote Teteke Titerakebo Yereqo' [ adot] [ tetec] [ titeracebo] [ jereco]}

The answer to this riddle is 'Meketekete TeTemuwe'. The literal definition of this riddle is by the time the mother and the son meet; they shout. In Gurage culture, it is very common to have coffee. The coffee is prepared to keep the proper cultural ceremony. Here, at the time of coffee preparation, it is mandatory to use the device to crash the roasted coffee, and then when it is ready, it will be served to people. This riddle expresses the match between the two coworkers in order to put effective and fruitful results for themselves and others at large. 


\section{2) 'Soset Etema; Chenemama Biema' [ soset] [ etema] [t $\square$ enemam] [ beama]}

This riddle simply translated into English as: The three sisters live around the area. The answer to this riddle is the traditional stove. In this riddle, the Gurage societies in culture have the practice to prepare the so-called 'Gonezeye' in the middle of the house. 'Gonezeye' means three and it is the traditional stove like structure which is prepared and presented around the center of the house to create beauty. Moreover, the purpose of 'Gonezeye' is not aesthetic beauty, but it is also used in the kitchen to make food.

\subsubsection{The issues of the comprehensive cultural context in relation to house building and} Agriculture

In all society, there are many events that make one group of people similar to others. Power relationship is a manifestation of it and a number of issues make them similar in society and it includes:- the culture of house building, agricultural culture, lifestyle, weeding, mourning, and others. Here, we are going to see the first two parameters. The agricultural products are effective in connection with the house building as replicated in many ways. Hereafter, some riddles concerned with the agricultural culture in connection with house building will be discussed.

\section{1) 'BanechenemieSemuteEneqiyefeme’ [ banet $\square$ enemea] [semut] [enekijefam]}

The answer of this riddle is 'Echeba'. Its meaning is defined as eight children were not given birth, but it hugs them. This riddle is also used to show the stand of the house which can have the power to handle other supportive branches hold together in order to make one huge house. This riddle has got its own implication in which the whole to be the aggregate of its part, and show how something becomes successful by the joint effort. Moreover, people go hand in hand to determine and work for success though there are a number of discrepancies in the whole life parameters. 
3.1.5. The direct interpretation of an utterance in the riddles about work and its fruit

1) 'Tetabera Yadot hema; Tetekuretese Yadot Gobesa Hema [ tetabera] [ jadot]

\section{[ hema] [ teterakos] [ jadot] [gobesa] [ hema]}

The answer of this riddle is bee and it is also translated as the bee feed like mother, but bit like Stepmother. In Gurage society, bee is taken as the sign of hard work and affords her honey to all humankind as a gift. On the contrary, when the bee is not handled properly, it attacks people which are considered as attacker. This riddle is used as an advice to the future and forget past mistake. It urges a person not to regret on what has not been done or was wrongly done in the past. It also leads to a competition in life that should not lag behind from others in the future.

2) 'EreseyeGerede Yechekuwerechen Ameber Yetem Hema' [ eresej] [ gered] [ jet $\square$ ecuwere $t \square e n]$ [ ameb:] [ jetem] [ hema]

The answer to this riddle is honey. It is to mean a cabbage prepared by a little girl is very delicious. A girl is symbolically associated with things prepared as it is very pleasant. It is already known that honey which is the byproduct of bee is so tasty and equally be presented as what is prepared by the little girl at home. We learn from this riddle that the size of something does not matter, and it is not the size rather it is wisdom that results great success in every parameters of life.

\subsubsection{Death and Destruction}

Death is one of the natural phenomena we all have to face in our life in this world and it is part and parcel of our life. Death and destruction are taken as disasters that cause the damage of honorable human life and property. In connection with this, as like other people, 
Gurage society expressed death and destruction as part of life through natural law. Here are selected examples of death and destruction.

\section{1) 'Mereyem Beremuden Tegegena Aneguweden' [merejem] [ beremuden]}

\section{[ tegegena] [ aneguweden]}

The answer of this riddle is dead body. It is translated as: Though I love the person when he was alive, by the time he passes away we never put in our side as the time of his life. It is evitable that man is mortal and death is natural which can reach across all human kind, but the dead body surely will not be put aside after death. On top of this, this riddle tells us that all human beings have a close attachment with our sibling and other human creature, but once we lose him/her by natural death; our relationship will automatically interrupt. By and large, the riddle clearly addresses the close connection between life and its consequence as natural incidents.

\section{2) 'BeshaEramena Jefewer Jefewere’' [ bet $\square$ a] [ eramena] [dzefer] [dzefer]}

Flood is the answer of this riddle. It has the following English equivalent: My red cow moves around. Now, the Gurage society makes a link between the floods with cows. This is to mean that the society makes enlightenment the importance of the cow with flood though we have negative outlook towards flood. This is because the improper utilization of flood results damage. Conversely, if we wisely use it, it will be equally important with the advantage that cows provide. This riddle is used to show that one has to analyze and consider the importance of the flood when it is utilized properly unless it will be the source of destruction. Thus, unwise utilization of it may cost us a lot.

\section{3) 'YeremuwejiBiremuwejiBe'ejeEtebuwechi' [jeremudzi] [biremudzi] [bedzi]}

The answer of this riddle is fire. This riddle is translated as: whatever we like it, we never touch with our hands. This riddle connotes that we insist badly the fire for various purposes and uses. However, it is totally impossible to put the fire with bare hands. As we 
know, the fire will benefit a lot to the people of the world in various ways and gives ultimate function for all human creatures though it has its own pitfalls. This does not mean that is discouraging to use it with great care. Thus, this riddle promotes the use of fire as it is vital for all users, but it demands everyone to be conscious how to use. This riddle connotes that every evil things will be handled with great care.

\subsection{The overall Nature of Gurage Riddle}

With regard to Gurage riddle, it is presented in the form of question and answer between two people or group of people. Its sentence Structures are both simple and sometimes compound sentences. Various issues are treated among various riddle. Most portions of the riddles are mentioned with great power of expressions. This is because the idea mentioned in the process of riddles is very much powerful to express idea within the community. Moreover, symbolically riddles are used in different ways to express various social, economic and .cultural issues.

\section{Discussion}

The ultimate goal of this paper is to show the way the Gurage's society riddle manipulates the language and structural analysis. It is intended to associate the language and structural analysis with regard to riddle in Gurage society. In this connection, the riddle has power to express the numerous life style, individual performance, indigenous knowledge, strong interpersonal relationship and personal behavior. The finding shows that there is high connection with the effort to bring social improvement through better accomplishment in various ups and down of life. The fact that Gurage people have riddles to characterize the definite moral and social values that point toward such parameters that exist in the Gurage culture. Likewise, it designates that in Gurage people are more concerned with 
those parameters worried with the riddle. According to Lakoff (1987), language is a conceptual phenomenon. This means that it depends on the theoretical aspects of the social life of the society. Thus, for instance, the riddle under 3.1.6 'Besha Eramena Jefewer Jefewere' This riddle literally translated as: My red cow move around. Now, the Gurage society makes a link between the floods with cows. This means that the society makes an enlightenment with the importance of the cow with flood though we have negative outlook towards flood. The finding also complies with Plack (2005) who asserted individuals and societal perceptions are influenced positively or negatively by social norms, and social powers and societal values. Moreover, the riddles undoubtedly presented the idea and societal philosophy released in order to show the hidden aspirations, feelings, perception, and practice exercised to depict through one of the literary works. What is more, they have more social norms such as hard work, interrelationship, joint effort, proper handle of natural and manmade resources, and the way to admit the natural death was treated well. The results of this paper advance the method of presentation describe the riddle linguistic nature, meaning and its culture of presentation. It was found that the riddles are simple in structure, impersonal dominantly in point view, and literal, metaphorical and pragmatic in meaning.

\section{Conclusion}

This study showed that riddle by very nature requires good understanding of both knowing of its meaning and the context in which the game has to be played and the interlocutor should know and respect and accept the norms to say it in order to get its intended meaning. It could be drawn that from the analysis most of the ideas of the riddles are social issues that give an insight about coexistence and mutual benefit with human kind and natural forces. In doing so, in the riddle the sentence level and linguistic analysis has been 
made so as to see its literary nature. The knowledge of Gurage people riddles which is wellthought-out as an asset as expressed in linguistic and structural analysis of the riddle showed that Gurage society has the culture of cultivation of 'Enset' and uses it for various social and cultural use. Besides, the community gives due recognition for solidarity, undertakes and recognizes with the death as natural phenomena, and the value to adopt with the community nearby them. Furthermore, this study has added to our level of consciousness on what has been interconnected and -determined with the riddle in specific and other literary works in wide-range circumstances on the attitude we have towards the representativeness and the culture of living. 


\section{References}

Armstrong, N. (2005). Translation, Linguistic, Culture: A French-English Handbook. USA:Cromwell Press Ltd.

Fairclough, N. (2003). Analyzing discourse: Textual analysis for social research.London and New York: Rutledge Taylor \&Francis Group.

Finnegan, R. (1970). Oral Literature in Africa. Oxford: Oxford University Press.

Gachanja, M. \& Kebaya, C. (2013). "Pedagogical Aspects of Riddles: A Critical Examination of Egakusii Riddles." International Journal of Humanities and Social Sciences Volume 3, Number 3, 2013. (pp.293-298). Available at www.ijhssnet.com/journals....../32p

Gebreyesus Hailemariam(1991). The Gurage and their culture. New York, Los Angeles: Vantage Press.

Gurage Zone Bahil Tourism and Communication (2012) [2004 E.C]. Yegurage wemaka.Welqite.

Leslau, W. (1951). Archaic features in south Ethiopic. Journal of the American Oriental Society, 71(4), 212-230.

Odaga, A. B. (1984). Yesterday's Today: The Study of Oral Literature. Nairobi: Lake Publishers and Enterprises.

Plack, M.M. (2005). „Human nature and research paradigms: Theory meets physical therapy practice ${ }^{e e}$. The Qualitative Report, 10(2), 223-245.

Sperber, D. \& Wilson (1986, 1995).Relevance: Communication and Cognition. Oxford. Blackwell.

Tenkir Tereda (1999) [1991 E.C.]. Temsayt, wemaka, mekmachot: Yebete-Gurage misaleyawi nigigiroch. Ethiopian Languages Study Center. Addis Ababa University. 